\title{
Response in bone turnover markers during therapy predicts overall survival in patients with metastatic prostate cancer: analysis of three clinical trials
}

\author{
A Som', S-M Tu', J Liu' ${ }^{2}$ X Wang ${ }^{2}$, W Qiao', C Logothetis' and PG Corn*,I \\ 'Department of Genitourinary Medical Oncology, Unit 1374, The University of Texas MD Anderson Cancer Center, 1 I 55 Herman Pressler, Houston, \\ TX 77230, USA; ' Department of Biostatistics, The University of Texas, MD Anderson Cancer Center, Houston, TX, USA
}

\begin{abstract}
BACKGROUND: The bone-forming metastases of prostate cancer result from complex stromal-epithelial interactions within the tumour microenvironment. Autocrine-paracrine signalling pathways between prostate cancer epithelial cells, osteoblasts, and osteoclasts stimulate aberrant bone remodelling, and the activity of these three cell populations can be quantitatively measured using prostatespecific antigen (PSA), bone-specific alkaline phosphatase (BAP) and urine N-telopeptide (UNTx), respectively. The purpose of the present study was to test the hypothesis that serial measurements of BAP and UNTx during therapy would facilitate monitoring of disease activity and predict the overall survival (OS) in patients with metastatic prostate cancer receiving therapy.

METHODS: Radionuclide bone scan, PSA, BAP, and UNTx data were retrospectively analysed from three clinical trials in patients with metastatic prostate cancer conducted at our institution. Qualitative changes in bone scans and quantitative changes in PSA, BAP, and uNTx concentrations during therapy were correlated with OS.

RESULTS: Baseline levels of BAP, but not PSA, were prognostic for OS in both androgen-dependent and castrate-resistant disease. A reduction in PSA, BAP, UNTx, or BAP/UNTx on therapy was predictive of improved OS in both patient groups. Conversely, an increase in PSA, or BAP on therapy was predictive of worse OS in both patient groups. Baseline number of lesions and response on bone scan during therapy were neither prognostic nor predictive of OS in either patient group.

CONCLUSION: These observations support the concept that serial measurements of bone turnover metabolites during therapy function as clinically informative predictive biomarkers in patients with advanced prostate cancer and skeletal metastases. PSA measurements and bone scans remain essential to monitor the overall disease activity and determine the anatomic distribution of skeletal metastases.

British Journal of Cancer (2012) 107, 1547-1553. doi: I0.1038/bjc.2012.436 www.bjcancer.com
\end{abstract}

Published online 2 October 2012

(C) 2012 Cancer Research UK

Keywords: prostate cancer; bone; predictive biomarkers; metastases

The clinical presentation of advanced, lethal prostate cancer is dominated by symptoms and findings caused by bone metastases. The formation of skeletal lesions in malignancy is associated with a disruption of the normal coupling between bone formation and bone resorption caused by the cancer epithelial cell (Logothetis and Lin, 2005; Logothetis et al, 2008). In most epithelial tumour types (breast, renal, lung), the net phenotype is 'bone-destructive', whereas in prostate cancer the net phenotype is 'bone-forming'. Autocrine and paracrine interactions between prostate cancer epithelial cells (the epithelial compartment) and bone stromal cells including osteoblasts and osteoclasts (the stromal compartment) in the bone microenvironment perturb the physiologic balance between bone-resorption and formation during metastasis development. The activity of these three cell populations can be quantitatively measured using prostate-specific antigen (PSA), bone-specific alkaline phosphatase (BAP) and urine $\mathrm{N}$-telopeptide (uNTx), respectively.

*Correspondence: Dr PG Corn; E-mail: pcorn@mdanderson.org Received II June 2012; revised 24 August 2012; accepted 30 August 2012; published online 2 October 2012
The striking predilection for prostate cancer to metastasise to bone has influenced the strategy to develop therapies that target the bone microenvironment. One approach has been 'bonetargeting' radionuclides such as strontium, samarium, and radium. These agents elicit reductions in PSA, BAP, and UNTx, and are clinically associated with improvements in bone pain and overall survival (OS) (Tu et al, 2001; Sartor, 2004; Sartor et al, 2011). One limitation of radionuclide therapy is myelosuppresion resulting from a lack of target cell specificity, as the delivered radiation dose kills hematopoietic cells in addition to prostate cancer and stromal cells. A second approach has been osteoclast-osteoblast inhibitors, including bisphosphonates (e.g., zolendronic acid) and RANKligand inhibitors (e.g., denosumab). Compared with radionuclides, these agents more specifically inhibit the stromal compartment rather than the epithelial compartment, as evidenced by reductions in bone turnover markers but not PSA (Saad et al, 2002; Fizazi et al, 2011; Saylor et al, 2011). Interestingly, however, although bisphosphonates and RANK-ligand inhibitors have consistently been shown to reduce pain and skeletal-related events, they do not prolong overall survival.

On the basis of the above considerations, there is continued interest in developing novel therapies that target both the epithelial 
and stromal compartments in bone (Dayyani et al, 2011). The development of 'bone-targeting therapies', however, has been hampered by the absence of informative biomarkers that can be used to monitor disease response in bone and predict clinical outcome measures such as OS. The currently accepted clinical instrument to evaluate skeletal metastases in patients with prostate cancer is the radionuclide bone scan (Dotan, 2008; Messiou et al, 2009). For newly diagnosed asymptomatic patients, bone scans are an essential tool to screen for the presence of occult skeletal metastases. In patients with established metastases, bone scans inform the clinicians about the anatomic distribution of lesions and facilitate the integration of local therapies (e.g., radiation and/ or surgery).

For several reasons, however, bone scans have limited utility in monitoring response and/or progression on active therapy. First, bone scans are not specific for cancer, as other nonmalignant processes that elicit bone turnover are also detected including Paget's disease, fractures, and infections. Second, after initiation of an effective systemic therapy, bone scans often demonstrate a 'flare' phenomenon that suggests disease progression, but in fact represents bone healing in response to tumour regression (Pollen et al, 1984). Indeed, bone scan flares can be difficult to differentiate radiographically from disease progression and oncologists often distinguish the two, clinically based on whether skeletal pain symptoms are improving or getting worse. Third, despite considerable effort, there are presently no accepted or validated methods to quantify bone scans (Imbriaco et al, 1998; Sabbatini et al, 1999; Sadik et al, 2006). Thus in clinical trials, bone scan changes remain a difficult metric on which to evaluate drug efficacy.

In this study, we sought to explore the potential for biochemical measurements of bone turnover metabolites measured serially on therapy to serve as clinically useful biomarkers in monitoring patients with metastatic prostate cancer receiving therapy. To do this, we retrospectively analysed data from three independent randomized clinical trials conducted at our institution. We evaluated the ability of baseline and serial measurements of BAP and UNTx on therapy to predict OS, and compared these results to those generated using PSA and bone scans. On the basis of our findings, we propose monitoring of BAP and UNTX in addition to PSA and bone scans in patients with metastatic disease receiving treatment. PSA levels reflect activity in the tumour epithelial compartment, BAP and uNTx levels reflect activity in the bone stromal compartment, and bone scans provide information about the anatomic location of skeletal metastases.

\section{PATIENTS AND METHODS}

\section{PSA, BAP, and uNTx measurements}

All PSA, BAP, and uNTx measurements were conducted in the Core Diagnostics Clinical Laboratory at MD Anderson Cancer Center. PSA levels were measured using an electrochemiluminescent ELISA immunoassy (Roche, Indianapolis, IN, USA). BAP levels were measured using the Access Ostase test, an electrochemiluminescent ELISA immunoassay (Beckman Coulter, Brea, CA, USA). uNTx levels were measured using a competitive immunoassay technique (VITROS Eci, Ortho Clinical Diagnostics, Rochester, NY, USA).

\section{Data collection}

To measure the associations between markers of bone metabolism and clinical outcome in both the androgen-dependent and the castrate-resistant disease states, data were retrospectively analysed from three clinical trials completed at MD Anderson Cancer Center. The first was a randomized phase II study in which patients with androgen-dependent metastatic prostate cancer received androgen deprivation therapy, doxorubicin $\left(20 \mathrm{mg} \mathrm{m}^{-2}\right.$ i.v. on days 1,8 , and 15 every 28 days for 2 cycles), and zoledronic acid ( 4 mg i.v. every 28 days for a total of 6 doses). Patients were randomized and assigned to receive either 1 dose of strontium- 89 ( $4 \mathrm{mCi}$ total dose) administered i.v. on the first day of treatment or no strontium-89 (Bilen et al, 2011). The second was a randomized phase II study in which patients with progressive metastatic castrate-resistant prostate cancer received docetaxel with or without imatinib (Mathew et al, 2007). The third was a phase I/II study in which patients with metastatic castrate-resistant prostate cancer received docetaxel and dasatinib (Araujo et al, 2012). In the androgen-dependent study, all patients $(n=66)$ received bisphosphonate therapy, as mandated by the protocol. In the two castrate-resistant studies $(n=125)$, bisphosphonate therapy was not mandated and only a minority of patients ( $2 \%$ and $13 \%$ in each trial, respectively) received it. To assess the therapy-specific effects on the bone microenvironment in patients with metastatic castrate-resistant disease, patients who received bisphosphonates $(n=17)$ were excluded from the subsequent analyses.

To assess the prognostic value of different biomarkers, baseline PSA, BAP, uNTx, BAP/uNTx, and bone scan data were correlated with OS in patients with androgen-dependent $(n=67)$ and castrate-resistant disease $(n=108)$. Baseline PSA, BAP, and uNTx values were measured within one month before trial enrolment. Baseline bone scans were assessed for the number of distinct lesions. To assess the predictive value of biomarker change in response to therapy, serial measurements of PSA, BAP, uNTx, and $\mathrm{BAP} / \mathrm{uNTx}$ during treatment were compared with baseline measurements, and changes were correlated with OS.

\section{Definitions}

Castrate-resistance Castrate-resistance was defined as disease progression despite having a serum testosterone level of $\leqslant 50 \mathrm{ng} \mathrm{dl}^{-1}$ (Scher and Sawyers, 2005).

Progression PSA, BAP, uNTx, and BAP/uNTx progression were defined as two consecutive rises $\geqslant 4$ weeks apart. Bone scan progression was defined as the appearance of $\geqslant 2$ new lesions, according to the Prostate Cancer Working Group 2 Criteria (Scher et al, 2008). Changes in biomarker concentrations were defined by subtracting the baseline from subsequent measurements during treatment. The decrease in biomarker concentration was defined as a difference of less than zero. A biomarker concentration was classified as not decreasing (no change or increasing), if the difference was greater than 0 .

\section{Overall survival}

The OS duration was defined as the time interval from the on trial date to the date of death. The last follow-up date was the latest date of any type of test or the date of the last follow-up examination.

\section{Statistical analysis}

Descriptive statistics, such as the mean, s.d., median, and range, were used to summarise the baseline measurements and changes in concentration of each biomarker during treatment. Frequencies and proportions were used to summarise the status of progression. Cox proportional hazards regression models were used to evaluate the association between OS duration and biomarker levels. The baseline values of PSA, BAP, and UNTX were log-transformed before being fitted in the model. To assess the correlation between the change of PSA and the changes of other markers over time in response to therapy, a Spearman's correlation coefficient was calculated for each patient. Wilcoxon signed-rank test was then used to determine the statistical significance of the correlations. 
The association between the changes of BAP and uNTX concentrations on therapy was analysed using Pearson's $\chi^{2}$ test.

To evaluate the association between an increase in biomarkers and OS duration, patients were grouped into four categories: (1) time to progression of less than 3 months, (2) time to progression of 3-6 months, (3) time to progression of 6-12 months, and (4) no progression greater than 12 months. Kaplan-Meier method was used to calculate the OS. Patients who were alive at the last followup date were censored in the analyses. A $P$-value $<0.05$ was deemed as statistically significant. All statistical analyses were conducted using the SAS (version 9.1; SAS Institute Inc., Cary, NC, USA) and S-PLUS (version 8.0; Insightful Corp., Seattle, WA, USA).

\section{RESULTS}

The primary goal of the present study was to test the hypothesis that changes in BAP and uNTx in response to therapy could predict OS in patients with metastatic prostate cancer. We chose OS rather than progression-free survival, as the relationship between the two has historically been weak in prostate cancer (Armstrong and Febbo, 2009). To do this, data were retrospectively analysed from three clinical trials completed at MD Anderson Cancer Center (Mathew et al, 2007; Bilen et al, 2011; Araujo et al, 2012). Although OS was not the primary end point of any of these trials, it was a secondary end point and long-term follow-up permitted analysis of OS in the present analysis.

The baseline characteristics of the patients are described in Table 1. Patients were divided into two groups, depending on whether they had androgen-dependent or castrate-resistant disease at study entry. Patients in both groups had high-volume bone disease with an average of $\geqslant 20$ lesions per patient. This was accompanied by high levels of PSA, BAP and uNTx at baseline. As bone-forming and -resorption processes are biologically coupled, we also analysed the ratio of BAP and uNTx to capture this dynamic relationship. This ratio was $<1$ in both patient groups at baseline.

We first tested the ability of baseline levels of PSA, BAP, uNTx, $\mathrm{BAP} / \mathrm{uNTx}$, and number of bone lesions to function as prognostic biomarkers in predicting OS. Table 2 shows results for androgendependent and castrate-resistant patients, respectively. Using a Cox proportional hazards model, only higher baseline levels of BAP were associated with reduced OS (hazard ratio $>1$ ) in both patients with androgen-dependent and castrate-resistant disease in a statistically significant manner. Higher baseline levels of BAP/ uNTx were prognostic in patients with androgen-dependent disease but not in patients with castrate-resistant disease. Higher baseline levels of uNTx were prognostic in patients with castrateresistant disease but not in patients with androgen-dependent disease. Higher baseline levels of PSA were prognostic in patients with castrate-resistant disease but not in patients with androgendependent disease, and baseline number of bone lesions was not prognostic in either group. Taken together, these data illustrate the potential for baseline BAP and UNTx measurements to function as prognostic biomarkers for patients with prostate cancer and skeletal metastases in both the androgen-dependent and castrateresistant disease states.

Table 3 provides the frequency of progression events during treatment for the androgen-dependent and castrate-resistant patients, respectively. PSA progression was the most frequent event and occurred in $\sim 50 \%$ of the patients in both groups. In contrast, bone scan progression occurred in $\sim 40 \%$ of patients with androgen-dependent disease and in only $\sim 11 \%$ of patients with castrate-resistant disease. Progression of at least one marker of bone metabolism occurred more frequently than bone scan progression in both groups. In patients with androgen-dependent disease, uNTx progression was more common than bone scan
Table I Baseline patient characteristics

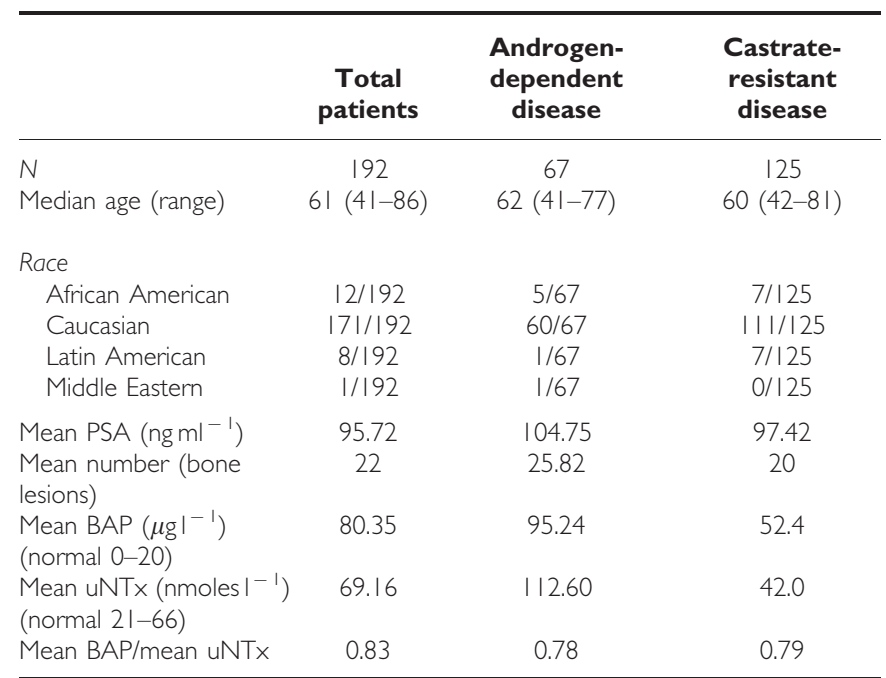

Abbreviations: $B A P=$ bone-specific alkaline phosphatase; PSA = prostate-specific antigen; $\mathrm{uNT} \times$ = urine $\mathrm{N}$-telopeptide.

Table 2 Cox PH model of overall survival for baseline markers in patients with androgen-dependent disease and skeletal metastases, and castrate-resistant disease and skeletal metastases

\begin{tabular}{|c|c|c|c|c|}
\hline \multirow[b]{2}{*}{ Variable } & \multicolumn{2}{|c|}{$\begin{array}{c}\text { Androgen-dependent } \\
\text { disease and skeletal } \\
\text { metastases }\end{array}$} & \multicolumn{2}{|c|}{$\begin{array}{l}\text { Castrate-resistant } \\
\text { disease and skeletal } \\
\text { metastases }\end{array}$} \\
\hline & HR (95\% Cl) & $P$-value & HR (95\% Cl) & $P$-value \\
\hline $\begin{array}{l}\text { Baseline } \\
\text { number of } \\
\text { lesions }\end{array}$ & $1.02(1.0,1.04)$ & 0.06 & $1.01(0.99,1.04)$ & 0.17 \\
\hline Baseline logPSA & | $(0.83,1.2)$ & 0.99 & $1.22(1.04,1.43)$ & 0.01 \\
\hline $\begin{array}{l}\text { Baseline } \\
\text { loguNTx }\end{array}$ & $1.47(0.95,2.26)$ & 0.08 & $1.62(1.15,2.29)$ & 0.01 \\
\hline Baseline logBAP & $1.46(1.05,2.04)$ & 0.03 & $1.46(1.11,1.91)$ & 0.01 \\
\hline $\begin{array}{l}\text { Baseline BAP/ } \\
\text { uNTx }\end{array}$ & $2.09(1.01,4.34)$ & 0.05 & $1.12(0.81,1.55)$ & 0.49 \\
\hline
\end{tabular}

Abbreviations: $\mathrm{BAP}=$ bone-specific alkaline phosphatase; $\mathrm{Cl}=$ confidence interval; $\mathrm{HR}=$ hazard ratio; PSA = prostate-specific antigen; $\mathrm{uNTx}=$ urine $\mathrm{N}$-telopeptide

progression ( $\sim 52 \%$ vs $40 \%$, respectively), whereas BAP progression occurred as often as bone scan progression $(\sim 40 \%)$. In patients with castrate-resistant disease, both BAP and uNTx progression occurred more frequently than bone scan progression ( $\sim 25 \%$ vs $\sim 25 \%$ vs $\sim 11 \%$, respectively). These data highlight the dynamic process of bone turnover evident in patients with metastatic prostate cancer receiving therapy.

Although the aberrant bone remodelling that takes place in prostate cancer is driven by autocrine/paracrine interactions between the epithelial and stromal compartments, we next tested whether PSA progression correlated with progression in bone markers or bone scan in all patients. There was a positive, statistically significant association between PSA progression with BAP progression, uNTx progression, and bone scan progression, but not with BAP/uNTx progression on therapy (Table 4). These data underscore the biological interaction between the epithelial and the stromal compartments in the pathogenesis of skeletal metastases in patients with advanced disease. Disease progression within the epithelial compartment is associated with increased modulation of the stromal compartment within the bone microenvironment. 
We next tested whether the changes in bone markers in response to therapy could predict OS. In androgen-dependent disease, a decrease in PSA or uNTx during therapy was significantly correlated with better OS when compared with no decrease (Table 5). In castrate-resistant disease, a decrease in PSA, BAP or BAP/uNTx was significantly correlated with better OS when compared with no decrease (Table 5). In contrast, resolution of one or more lesions on bone scan during therapy did not predict for an improved OS in either disease state. These results demonstrate that responses in bone biomarkers, but not bone scans during therapy, are predictive of better OS in patients with advanced metastastic prostate cancer receiving therapy.

To test the corollary hypothesis that progression in bone biomarkers would predict reduced OS, we stratified biomarker progression times into four categories: (1) $<3$ months, (2) between 3 and 6 months, (3) between 6 and 12 months, and (4)

Table 3 Summary of progression events in patients with androgendependent disease and skeletal metastases, and castrate-resistant disease and skeletal metastases

\begin{tabular}{|c|c|c|c|c|}
\hline \multirow[b]{2}{*}{ Variable } & \multicolumn{2}{|c|}{$\begin{array}{c}\text { Androgen-dependent } \\
\text { disease and skeletal } \\
\text { metastases }\end{array}$} & \multicolumn{2}{|c|}{$\begin{array}{l}\text { Castrate-resistant disease } \\
\text { and skeletal metastases }\end{array}$} \\
\hline & Progression & $\mathbf{N}(\%)$ & Progression & $\mathbf{N}(\%)$ \\
\hline \multirow[t]{2}{*}{ Bone scan } & No & $42(62.7)$ & No & $96(88.9)$ \\
\hline & Yes & $25(37.3)$ & Yes & $12(11.1)$ \\
\hline \multirow[t]{2}{*}{ PSA } & No & 33 (49.3) & No & $56(51.9)$ \\
\hline & Yes & $34(50.7)$ & Yes & $52(48.1)$ \\
\hline \multirow[t]{2}{*}{ BAP } & No & $4 \mid(61.2)$ & No & $82(75.9)$ \\
\hline & Yes & $26(38.8)$ & Yes & $26(24.1)$ \\
\hline \multirow[t]{2}{*}{ uNTx } & No & $32(47.8)$ & No & 81 (75) \\
\hline & Yes & $35(52.2)$ & Yes & $27(25)$ \\
\hline \multirow[t]{2}{*}{ BAP/uNTx } & No & $54(80.6)$ & No & 85 (78.7) \\
\hline & Yes & $13(19.4)$ & Yes & $23(21.3)$ \\
\hline
\end{tabular}

Abbreviations: $\mathrm{BAP}=$ bone-specific alkaline phosphatase; $\mathrm{PSA}=$ prostate-specific antigen; $\mathrm{UNT} x=$ urine $N$-telopeptide

Table 4 Correlations between progression in PSA and other biomarkers

\begin{tabular}{lcl}
\hline Progression in & $\begin{array}{c}\text { PSA progression } \\
\text { (correlation coefficient) }\end{array}$ & $\boldsymbol{P}$-value \\
\hline Bone scan & 0.27 & 0.0002 \\
BAP & 0.24 & 0.0006 \\
UNTx & 0.14 & 0.0076 \\
BAP/UNTx & 0.09 & 0.15 \\
\hline
\end{tabular}

Abbreviations: $\mathrm{BAP}=$ bone-specific alkaline phosphatase; $\mathrm{PSA}=$ prostate-specific antigen; $\mathrm{uNT} \times=$ urine $\mathrm{N}$-telopeptide
$>12$ months. Kaplan-Meier plots depicting OS for androgendependent $(n=67)$ and castrate-resistant patients $(n=108)$ are shown in Figures $1 \mathrm{~A}$ and $2 \mathrm{~A}$, respectively. In patients with androgen-dependent disease, progression in PSA or BAP predicted for reduced OS in a statistically significant manner (Figures 1B and $\mathrm{C}$ ). In contrast, progression in BAP/uNTx did not predict reduced OS (Figure 1D). For both BAP and BAP/uNTx categories, there were too few androgen-dependent patients to include a $<3$ months of progression time group.

In patients with castrate-resistant disease, progression in PSA, $\mathrm{BAP}$, or BAP/uNTx on therapy each predicted for reduced OS in a statistically significant manner. (Figures 2B-D). Survival for patients with $\mathrm{PSA}, \mathrm{BAP}$, or $\mathrm{BAP} / \mathrm{uNTx}$ progression times $<3$ months was shorter than patients with progression times $>12$ months. Patients with progression times between 3 and 12 months experienced the survival probabilities between these two categories for BAP and BAP/uNTX, but not PSA. Neither bone scan progression nor UNTx progression on therapy predicted for OS in either patients with androgen-dependent disease or castrateresistant disease (data not shown).

\section{DISCUSSION}

Advanced prostate cancer is dominated by bone metastases and results from clinical studies support the hypothesis that bonetargeting therapies can improve the OS. For example, alpharadin (radium-223 chloride) was recently reported to prolong survival in a double-blind, randomized, Phase III trial (ALYSYMPCA) in patients with castrate-resistant disease and skeletal metastases (Parker et al, 2012). At present, however, a relatively limited ability to monitor prostate cancer bone metastasis during therapy has impeded research efforts to develop novel bone-targeting agents. Thus, there is a growing imperative to develop better methods to monitor skeletal disease activity during therapy that correlate with clinically meaningful outcomes such as OS. The prevailing strategy to overcome this limitation includes the development of imaging techniques that permit improved discrimination between malignant and nonmalignant bone lesions, 'pixel quantitation' of metastatic lesions, and improved standardisation, acquisition, and reporting of imaging data. Some of these techniques were build on existing technetium-99m-MDP radionuclide scintigraphy, while others are incorporating MRI and PET scan methodologies (Imbriaco et al, 1998; Sabbatini et al, 1999; Sadik et al, 2006; Messiou et al, 2011). Studies are presently ongoing to determine the utility of these approaches.

As an alternative strategy, in the present study we describe an approach to monitor the activity of prostate cancer in bone on therapy using biochemical markers that reflect the underlying biology of the complex interaction between cancer epithelial cells, osteoblasts, and osteoclasts within the tumour bone microenvironment. We found that reductions in BAP and/or uNTx on therapy function as predictive biomarkers for improved OS in patients

Table 5 Cox proportional hazard's model of overall survival duration according to changes in marker concentrations in patients with androgen-dependent disease and changes in marker concentrations in patients with castrate-resistant disease

\begin{tabular}{|c|c|c|c|c|}
\hline \multirow[b]{2}{*}{ Variable } & \multicolumn{2}{|c|}{$\begin{array}{c}\text { Changes in marker concentrations in patients with } \\
\text { androgen-dependent disease }\end{array}$} & \multicolumn{2}{|c|}{$\begin{array}{c}\text { Changes in marker concentrations in patients with } \\
\text { castrate-resistant disease }\end{array}$} \\
\hline & HR $(95 \% \mathrm{Cl})$ & $P$-value & HR (95\% Cl) & $P$-value \\
\hline PSA (decrease vs no decrease) & $0.18(0.06,0.51)$ & 0.001 & $0.49(0.3,0.81)$ & 0.01 \\
\hline BAP (decrease vs no decrease) & $0.31(0.04,2.47)$ & 0.27 & $0.31(0.16,0.58)$ & 0.0003 \\
\hline uNTx (decrease vs no decrease) & $0.25(0.05,1.14)$ & 0.05 & $0.6(0.35,1.02)$ & 0.06 \\
\hline BAP/uNTx (decrease vs no decrease) & $0.46(0.14,1.51)$ & 0.2 & $0.26(0.14,0.49)$ & $<0.0001$ \\
\hline
\end{tabular}

Abbreviations: $\mathrm{BAP}=$ bone-specific alkaline phosphatase; $\mathrm{Cl}=$ confidence interval; $\mathrm{HR}=$ hazard ratio; PSA = prostate-specific antigen; uNTx = urine $\mathrm{N}$-telopeptide. 

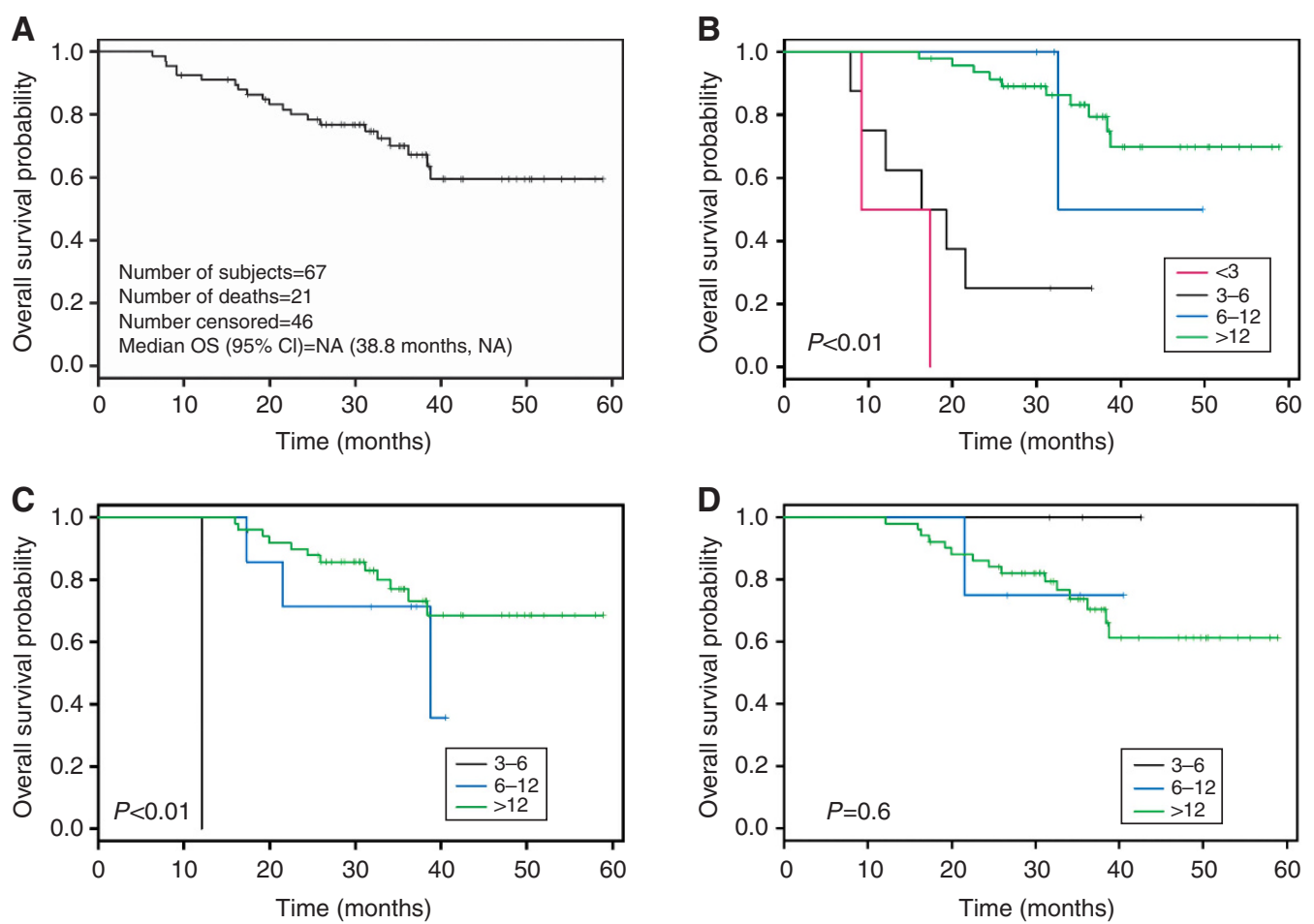

Figure I (A) Kaplan-Meier curve for overall survival duration in patients with androgen-dependent disease. (B) Kaplan-Meier curves for overall survival duration by time to PSA progression in patients with androgen-dependent disease. (C) Kaplan-Meier curves for overall survival duration by time to BAP progression in patients with androgen-dependent disease. (D) Kaplan-Meier curves for overall survival duration by time to BAP/uNTx progression in patients with androgen-dependent disease.
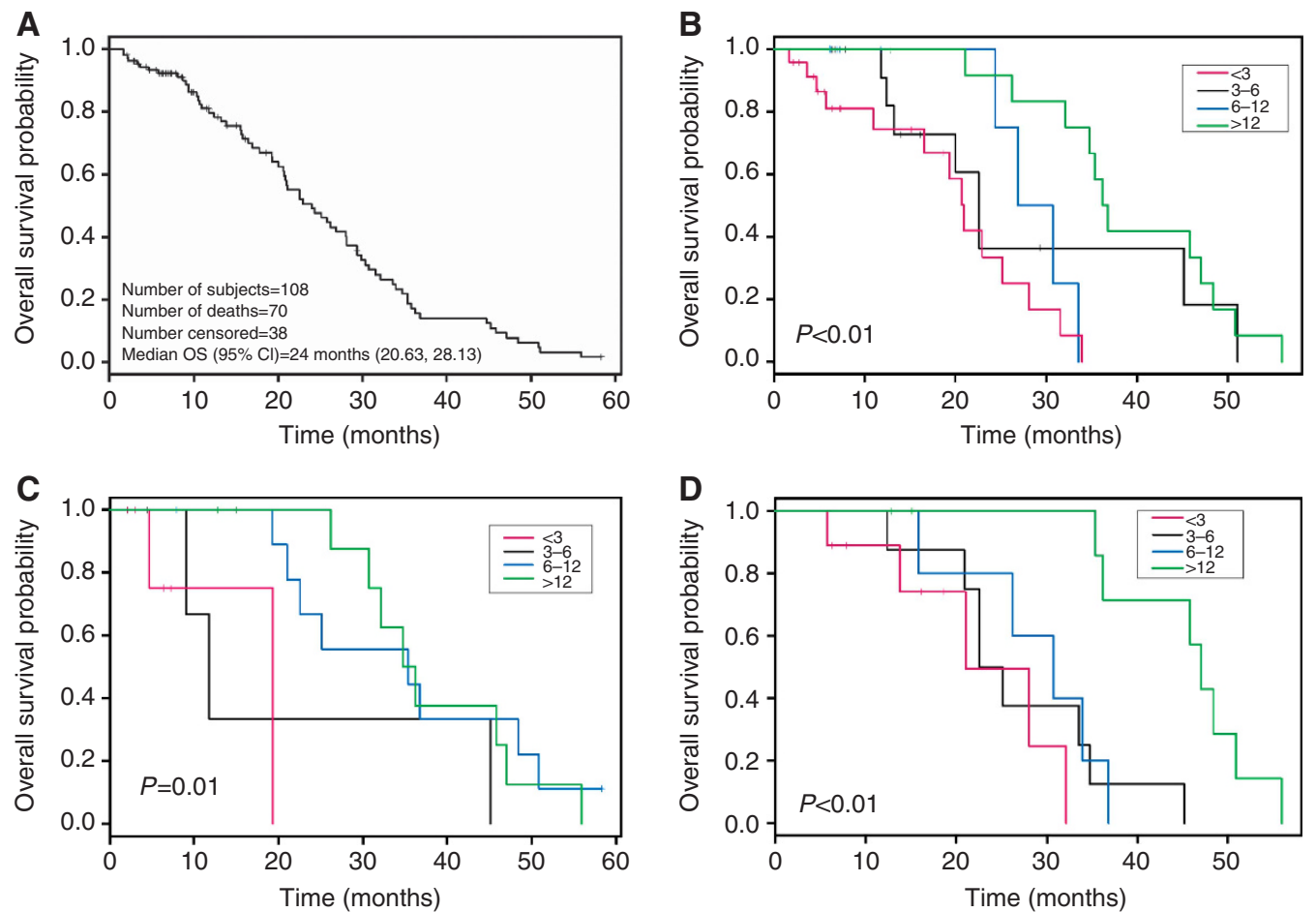

Figure 2 (A) Kaplan-Meier curve for overall survival duration in patients with castrate-resistant disease. (B) Kaplan-Meier curves for overall survival duration by time to PSA progression in patients with castrate-resistant disease. (C) Kaplan-Meier curves for overall survival duration by time to BAP progression in patients with castrate-resistant disease. (D). Kaplan-Meier curves for overall survival duration by time to BAP/uNTx progression in patients with castrate-resistant disease. 
with skeletal metastases receiving cytotoxic therapy in both the androgen-dependent and the castrate-resistant settings. In contrast, increases in BAP and/or UNTX predicted for worse OS in castrate-resistant but not in androgen-dependent patients. Bone scan responses during therapy were not predictive of OS. These data support the hypothesis that serial measurements of bone turnover markers permit efficient monitoring of response and clinical efficacy in patients with bone metastases on therapy.

One limitation of our analysis was that we were unable to specifically test the effects of bisphophonates (e.g., zolendronic acid) or RANK-ligand inhibitors (e.g., denosumab) as an independent variable on clinical outcome. In the studies we analysed, all androgen-dependent patients had received bisphosphonates, all castrate-resistant patients had not, and all the 3 studies were conducted before the approval of denosumab. Both classes of agents have been demonstrated to prevent bone loss in patients with androgen-dependent disease receiving androgen deprivation therapy, and modulate BAP and UNTX in patients with advanced castrate-resistant disease (Smith et al, 2001, 2009; Fizazi et al, 2011; Smith et al, 2011). In addition, normalisation of bone markers in response to zolendronic acid predicts for improved OS in patients with castrate-resistant disease (Lipton et al, 2008). However, as neither class has been shown to prolong OS, we conclude that cytotoxic anticancer therapies were responsible for the dominant effects on survival observed in our study.

Although baseline BAP and uNTx levels have previously been shown to have prognostic significance in patients with metastatic prostate cancer, our results are the first to demonstrate the ability of changes in these measurements during therapy to serve as predictive biomarkers for OS (Cook et al, 2006). Our data are of particular interest, as many novel epithelial-stromal bonetargeting agents are tyrosine kinase inhibitors (including inhibitors of Src, c-Met and VEGFR2) that demonstrate significant clinical activity without reductions in PSA. For example, mCRPC patients treated with the combined c-Met/ VEGR2 inhibitor cabozantinib (XL-184) experience high rates of pain relief, reductions in lymphadenopathy, and responses in bone scan associated with declines in bone turnover markers but not PSA (Hussain et al, 2011). Thus, for some novel drugs that provide benefit without a corresponding reduction in PSA, a reduction in bone turnover markers provides additional objective evidence that the drug is modulating the tumour microenvironment in a therapeutically favourable manner.

At our institution, we have adopted an integrated approach to evaluate novel therapies in patients with skeletal metastases (Dayyani et al, 2011). First, our clinical research studies include the routine incorporation of serial (pre-, on-, and post-therapy) trans-iliac bone marrow biopsies to permit direct analysis of therapy effects on the tumour epithelial and the bone stromal compartments over time (Efstathiou et al, 2012). Second, prompted by either skeletal symptoms or the need to determine the anatomic distribution of metastases, we perform serial radionuclide bone scans. We also routinely incorporate CT scans to further define clinically relevant anatomic features of individual lesions, including condition of the bone cortex, risk for fracture, and presence of atypical osteolytic, 'bone-destructive' changes (seen in a subset of patients with metastatic castrate-resistant disease). Third, on the basis of the data presented in this study, serial measurements of PSA, BAP, and UNTx are obtained to monitor the disease activity in prostate cancer epithelial cells and the principal host stromal cells (osteoblasts and osteoclasts) involved in the pathological remodelling of bone. Using this integrated approach, bone imaging is used to manage symptoms and determine the anatomic distribution of metastases, PSA is used to monitor the epithelial compartment, and bone turnover markers (BAP, uNTx) are used to monitor bone metastases.

\section{REFERENCES}

Araujo JC, Mathew P, Armstrong AJ, Braud EL, Posadas E, Lonberg M, Gallick GE, Trudel GC, Paliwal P, Agrawal S, Logothetis CJ (2012) Dasatinib combined with docetaxel for castration-resistant prostate cancer: results from a phase 1-2 study. Cancer 118(1): 63-71

Armstrong AJ, Febbo PG (2009) Using surrogate biomarkers to predict clinical benefit in men with castration-resistant prostate cancer: an update and review of the literature. Oncologist 14(8): 816-827

Bilen MA, Liu D, Mathew P, Pagliaro LC, Logothetis CJ, Araujo J, Aparicio A, Corn PG, Hadjenberg J, Dakhil SR, Tu S (2011) A randomized phase II study of bone-targeted therapy in advanced androgen-dependent prostate cancer. J Clin Oncol 29(suppl) abstract 4649

Cook RJ, Coleman R, Brown J, Lipton A, Major P, Hei YJ, Saad F, Smith MR (2006) Markers of bone metabolism and survival in men with hormonerefractory metastatic prostate cancer. Clin Cancer Res 12(11 Pt 1): 3361-3367

Dayyani F, Gallick GE, Logothetis CJ, Corn PG (2011) Novel therapies for metastatic castrate-resistant prostate cancer. J Natl Cancer Inst 103(22): $1665-1675$

Dotan ZA (2008) Bone imaging in prostate cancer. Nat Clin Pract Urol 5(8): $434-444$

Efstathiou E, Titus M, Tsavachidou D, Tzelepi V, Wen S, Hoang A, Molina A, Chieffo N, Smith LA, Karlou M, Troncoso P, Logothetis CJ (2012) Effects of abiraterone acetate on androgen signaling in castrate-resistant prostate cancer in bone. J Clin Oncol 30(6): 637-643

Fizazi K, Carducci M, Smith M, Damiao R, Brown J, Karsh L, Milecki P, Shore N, Rader M, Wang H, Jiang Q, Tadros S, Dansey R, Goessl C (2011) Denosumab versus zoledronic acid for treatment of bone metastases in men with castration-resistant prostate cancer: a randomised, doubleblind study. Lancet 377(9768): 813-822

Hussain M, Smith MR, Sweeney C, Corn PG, Elfiky A, Gordon MS, Hass NB, Harzstark AL, Kurzrock R, Lara P, Lin C, Sella A, Small E, Spira A, Vaishampayan U, Vogelzang N, Scheffold C, Ballinger MD, Schimmoller F, Smith DC (2011) Cabozantinib (XL184) in metastatic castration-

resistant prostate cancer (mCRPC): results from a phase II randomized discontinuation trial. ASCO (suppl): abstract 4516

Imbriaco M, Larson SM, Yeung HW, Mawlawi OR, Erdi Y, Venkatraman ES, Scher HI (1998) A new parameter for measuring metastatic bone involvement by prostate cancer: the Bone Scan Index. Clin Cancer Res 4(7): 1765-1772

Lipton A, Cook R, Saad F, Major P, Garnero P, Terpos E, Brown JE, Coleman RE (2008) Normalization of bone markers is associated with improved survival in patients with bone metastases from solid tumors and elevated bone resorption receiving zoledronic acid. Cancer 113(1): 193-201

Logothetis CJ, Lin SH (2005) Osteoblasts in prostate cancer metastasis to bone. Nat Rev Cancer 5(1): 21-28

Logothetis CJ, Navone NM, Lin SH (2008) Understanding the biology of bone metastases: key to the effective treatment of prostate cancer. Clin Cancer Res 14(6): 1599-1602

Mathew P, Thall PF, Bucana CD, Oh WK, Morris MJ, Jones DM, Johnson MM, Wen S, Pagliaro LC, Tannir NM, Tu SM, Meluch AA, Smith L, Cohen L, Kim SJ, Troncoso P, Fidler IJ, Logothetis CJ (2007) Plateletderived growth factor receptor inhibition and chemotherapy for castration-resistant prostate cancer with bone metastases. Clin Cancer Res 13(19): 5816-5824

Messiou C, Collins DJ, Giles S, de Bono JS, Bianchini D, de Souza NM (2011) Assessing response in bone metastases in prostate cancer with diffusion weighted MRI. Eur Radiol 21(10): 2169-2177

Messiou C, Cook G, deSouza NM (2009) Imaging metastatic bone disease from carcinoma of the prostate. Br J Cancer 101(8): 1225-1232

Parker C, Nilsson S, Heinrich D, O'Sullivan JM, Fossa SD, Chodacki A, Wiencho PJ, Logue JP, Seke M, Widmark A, Johannessen DC, Hoskin P, Bottomley D, Coleman RE, Vogelzang NJ, O'Bryan-Tear CG, Garcia-Vargas JE, Shan M, Sartor AO (2012) Updated analysis of the phase III, double-blind, randomized, multinational study of radium223 chloride in castration-resistant prostate cancer (CRPC) patients 
with bone metastases (ALSYMPCA). J Clin Oncol (suppl): abstract LBA4512

Pollen JJ, Witztum KF, Ashburn WL (1984) The flare phenomenon on radionuclide bone scan in metastatic prostate cancer. AJR Am J Roentgenol 142(4): 773-776

Saad F, Gleason DM, Murray R, Tchekmedyian S, Venner P, Lacombe L, Chin JL, Vinholes JJ, Goas JA, Chen B (2002) A randomized, placebocontrolled trial of zoledronic acid in patients with hormone-refractory metastatic prostate carcinoma. J Natl Cancer Inst 94(19): 1458-1468

Sabbatini P, Larson SM, Kremer A, Zhang ZF, Sun M, Yeung H, Imbriaco M, Horak I, Conolly M, Ding C, Ouyang P, Kelly WK, Scher HI (1999) Prognostic significance of extent of disease in bone in patients with androgen-independent prostate cancer. J Clin Oncol 17(3): 948-957

Sadik M, Jakobsson D, Olofsson F, Ohlsson M, Suurkula M, Edenbrandt L (2006) A new computer-based decision-support system for the interpretation of bone scans. Nucl Med Commun 27(5): 417-423

Sartor O (2004) Overview of samarium sm 153 lexidronam in the treatment of painful metastatic bone disease. Rev Urol 6(Suppl 10): S3-S12

Sartor O, Goeckeler W, Bruland O (2011) Stromal targeted therapy in bone metastatic prostate cancer: promise delivered. Asian J Androl 13(6): 783-784

Saylor PJ, Lee RJ, Smith MR (2011) Emerging therapies to prevent skeletal morbidity in men with prostate cancer. J Clin Oncol 29(27): 3705-3714

Scher HI, Halabi S, Tannock I, Morris M, Sternberg CN, Carducci MA, Eisenberger MA, Higano C, Bubley GJ, Dreicer R, Petrylak D, Kantoff P, Basch E, Kelly WK, Figg WD, Small EJ, Beer TM, Wilding G, Martin A,
Hussain M (2008) Design and end points of clinical trials for patients with progressive prostate cancer and castrate levels of testosterone: recommendations of the Prostate Cancer Clinical Trials Working Group. I Clin Oncol 26(7): 1148-1159

Scher HI, Sawyers CL (2005) Biology of progressive, castration-resistant prostate cancer: directed therapies targeting the androgen-receptor signaling axis. J Clin Oncol 23(32): 8253-8261

Smith MR, Egerdie B, Hernandez TN, Feldman R, Tammela TL, Saad F, Heracek J, Szwedowski M, Ke C, Kupic A, Leder BZ, Goessl C (2009) Denosumab in men receiving androgen-deprivation therapy for prostate cancer. $N$ Engl J Med 361(8): 745-755

Smith MR, McGovern FJ, Zietman AL, Fallon MA, Hayden DL, Schoenfeld DA, Kantoff PW, Finkelstein JS (2001) Pamidronate to prevent bone loss during androgen-deprivation therapy for prostate cancer. $N$ Engl J Med 345(13): 948-955

Smith MR, Saad F, Coleman R, Shore N, Fizazi K, Tombal B, Miller K, Sieber P, Karsh L, Damiao R, Tammela TL, Egerdie B, Van PH, Chin J, Morote J, Gomez-Veiga F, Borkowski T, Ye Z, Kupic A, Dansey R, Goessl C (2011) Denosumab and bone-metastasis-free survival in men with castration-resistant prostate cancer: results of a phase 3, randomised, placebo-controlled trial. Lancet 379(9810): 39-46

Tu SM, Millikan RE, Mengistu B, Delpassand ES, Amato RJ, Pagliaro LC, Daliani D, Papandreou CN, Smith TL, Kim J, Podoloff DA, Logothetis CJ (2001) Bone-targeted therapy for advanced androgen-independent carcinoma of the prostate: a randomised phase II trial. Lancet 357(9253): 336-341

This work is published under the standard license to publish agreement. After 12 months the work will become freely available and the license terms will switch to a Creative Commons Attribution-NonCommercial-Share Alike 3.0 Unported License. 